\section{И.А. СОЛНЦЕВА}

Медицинский центр ГУП «Адмиралтейские Верфи», г. Санкт-Петербург

\section{РОЛЬ ЭХОГРАФИИ В ДИАГНОСТИКЕ ДИФФУЗНОГО ФИБРОАДЕНОМАТОЗА МОЛОЧНЫХ ЖЕЛЕЗ}

Традиционные методы исследования молочных желез не обеспечивают достаточно высокий уровень диагностики патологии этого органа.

Необходимо использовать новые методики, в числе которых следует отметить УЗисследование. Эхография имеет широкие возможности в диагностике различных заболеваний молочных желез, а при диффузном

фиброаденоматозе является предпочтительным методом.

Автором отмечены основные достоинства УЗ-исследования, а также разработаны количественные критерии, позволяющие четче

диагностировать патологию и определять тяжесть заболевания.

\section{Введение}

В настоящее время в комплекс основных методов исследования молочных желез входят: традиционное клиническое обследование, рентгеновская маммография, эхография, тепловизионное исследование, компьютерная томография, магнитно-резонансная томография и тонкоигольная пункционная биопсия.

Однако несмотря на большое количество методов и пристальный интерес $\kappa$ вопросу ранней $\partial u$ агностики заболеваний молочных желез, заболеваемость раком молочной железы возрастает год от года. Неудовлетворенность результатами диагностики диктует необходимость использования новых методик. Это цветовое допплеровское картирование, применение энергетического допплера и контрастной эхографии.

Их использование в эхографии молочных желез пока находится в стадии становления. Но результаты исследований позволяют говорить о перспективности этих методик. Уже сейчас они могут оказать реальную помощь в мониторинге больных раком молочной железы, подвергающихся на первом этапе лечения лучевой и/или химиотерапии.

В последние годь ультразвуковое исследование заняло прочное положение в арсенале методов диагностики заболеваний молочных желез. Вначале, применяясь после рентгеновской маммографии, метод использовался только для дифференциальной диагностики кистозных и солидных образований. Но с появлением высокочастотных датчиков возможности его значительно расширились.

Практика показала, что эхография высокоинформативна в тех случаях, когда результаты рент- геновской маммографии сомнительны при рентгенологически «плотных» железах. Метод эхографии не имеет противопоказаний и может применяться у молодых женщин (до 35 лет), у детей, при беременности и лактации.

К несомненным положительным чертам УЗ-метода можно отнести также возможность его применения в острый период травмъ и воспаления, возможность обследования грудных желез у мужчин, проведение пункционной биопсии под контролем ультразвука, а также исследование состояния эндопротезов молочных желез.

На настоящий момент разработана достаточно четкая эхосемиотика узловых образований молочных желез. Но в то же время есть вопросы, недостаточно освещенные в литературе. Это проблемы эхографических критериев и эхографической классификащии диффузного фиброаденоматоза молочных желез. Для исследования молочных желез при диффузном фиброаденоматозе методом выбора является эхография, так как она дает возможность многократного динамического контроля у женщин всех возрастных групп и не имеет отрицательного лучевого воздействия. Тот факт, ито в настоящее время от 40 до 50\% женщин страдают диффузными дисгормональными заболеваниями молочных желез, к которым относится и фиброаденоматоз, делает вопрос развития метода эхографии еще более актуальным.

Однако отсутствие четких эхографических ориентиров и как результат - субъективный подход ведут к тому, что в заключениях специалистов нет преемственности. Врач не в состоянии оченить динамику прочесса, опираясь на 
Таблица

Зависимость толщины слоя железистой ткани и показателей эхоплотности от возраста в контрольной группе

\begin{tabular}{|l|c|c|c|c|}
\hline \multirow{2}{*}{ Изучаемье параметрьь } & \multicolumn{4}{|c|}{ Возрастная группа } \\
\cline { 2 - 5 } & До 35 лет & $35-44$ года & $45-54$ года & 54 u $>$ лет \\
\hline \hline Толщинаслоя железистойткани (мм) & 12,4 & 10,3 & 8,4 & 5,6 \\
\hline \hline Показатели эхоплотности (усл. ед.) & $26-33$ & $26-37$ & $34-40$ & $36-44$ \\
\hline
\end{tabular}

Таблица 2

Симптомокомплексы различных эхографических вариантов ФАМ

\begin{tabular}{|c|c|c|c|c|}
\hline \hline \multirow{2}{*}{$\begin{array}{l}\text { Эхосимптоломы диффуз- } \\
\text { ногроаденоматоза }\end{array}$} & \multicolumn{3}{|c|}{ Эхографический вариант фиброаденоматоза } \\
\cline { 2 - 5 } & железистый & кистозный & фибрознъй & смешанный \\
\hline \hline Железистая гиперплазия & + & - & \pm & + \\
\hline \hline Фиброзные изменения & - & + & + & \pm \\
\hline \hline Кистьь & - & + & \pm & + \\
\hline \hline Дуктэтазия & \pm & - & \pm & \pm \\
\hline
\end{tabular}

Рис. 1. Методика измерения толщины

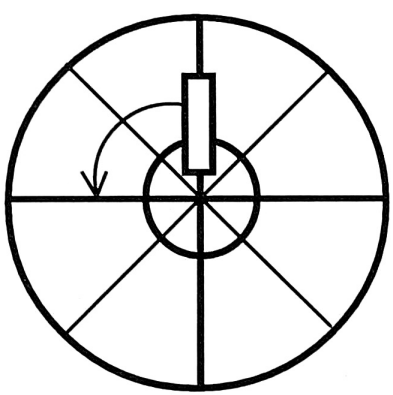

железистого слоя

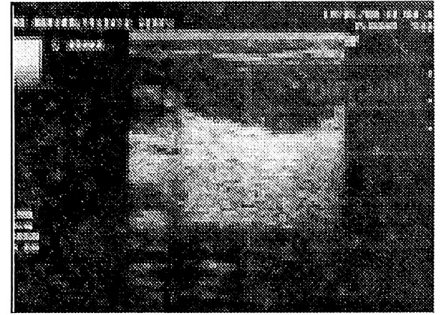

Эхографию проводили на аппаpame «Logiq-500» фирмы «GE» $C$ использованием линейного датчика с частотой 7,5 Мгu.

Стандартная методика исследования молочных желез дополнялась измерением толщины паренхимы (слоя железистой ткани) в каждом секторе молочной железы вдоль воображаемых радиар- чужое заключение, поскольку в описаниях отсутствуют какиелибо объективные критерии.

\begin{tabular}{|c|}
\hline Цель \\
\hline $\begin{array}{l}\text { Целью нашей работы был по- } \\
\text { иск объективных (количествен- } \\
\text { ных) критериев оченки эхографи- } \\
\text { ческого изображения при диффуз- } \\
\text { ном фиброаденоматозе молочных } \\
\text { желез. }\end{array}$ \\
\hline
\end{tabular}

\footnotetext{
Материаль и методы

Мы провели эхографическое обследование молочных желез у 221 пациентки в возрасте от 21 до 72 лет. Из них 61 женщина составила контрольную группу без клинических проявлений заболеваний молочных желез, а 161 женщина - группу с клиническим диагнозом диффузныци фиброаденоматоз.
}

Рис. 2. Методика измерения показателей эхоплотности: 25, 27, 29 - показатели эхоплотности железистой ткани, 17, 18 - показатели эхоплотности жировой ткани

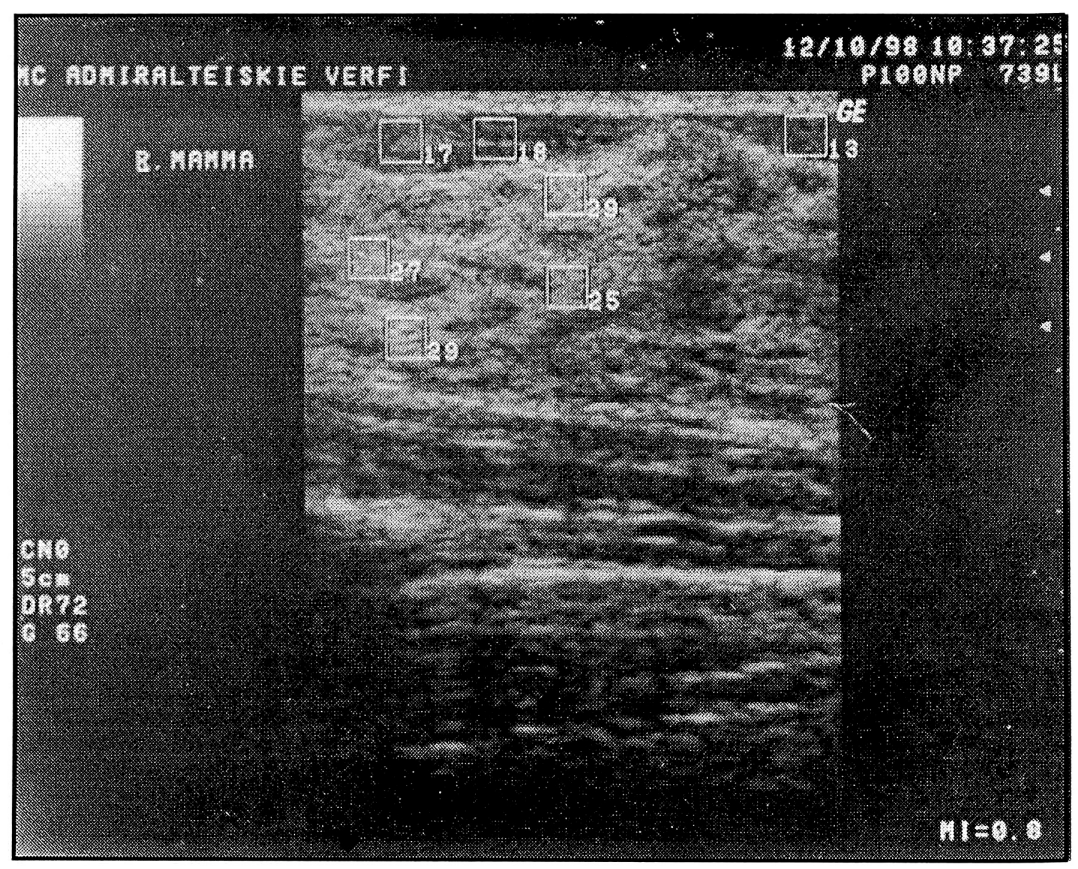


ньх линий, сходящихся к соску (рис. 1), и определением показателей эхоплотности железистой ткани (рис. 2).

Для измерения показателей эхоплотности мы использовали функцию «Echo-level», что не представляет каких-либо технических трудностей. Единственное условие для получения сопоставимых результатов - это одинаковые настройки аппарата. В наших исследованиях: глубина сканирования - 4 см, усиление (Gain) - 66, динамический диапазон (Dynamic Range) - 72 .

\section{Результаты и обсуждение}

Полученные при исследовании контрольной группь женщин результаты показали, что толщина слоя железистой ткани колебалась от 5 до 14 мм в зависимости от возраста женщин. Показатели эхоплотности такэе варьировали в зависимости от возраста. Мы выделили 3 группь значений этих показателей: средние (26-32), повышенные (33-37), значительно повышенные (38-44).

С возрастом отчетливо прослеживается тенденция к уменьшению толщины слоя железистой ткани и повышению показателей эхоплотности вплоть до максимальных значений у женщин старше 54 лет (табл. 1).

Такая зависимость отражает нормально протекающие в молочных железах процессы возрастной инволющии. Эти процессы проявляются жировой трансформащией железистой ткани, что приводит к уменьшению ее количества и, соответственно, к уменьшению толщины ее слоя, а также диффузным фиброзированием тканей молочной железы, что проявляется постепенным повышением показателей эхоплотности.

Исходя из этого можно сделать вывод, что в нормальной молочной железе сохранено гармоничное соотношение между фиброзной и железистой тканью и структура железы физиологически соответствует возрасту (рис. 3, 4, 5).
При исследовании женщин с клиническим диагнозом диффузный фиброаденоматоз в 76\% случаев определялось утолщение слоя железистой ткани от 15 до 33 мм, а показатели эхоплотности не соответствовали возрасту.

Мы расценили это как допол-

Рис. 3. Эхограмма молочной железы пациентки 25 лет. Репродуктивный тип строения. Толщина слоя железистой ткани - 14 мм.

Показатели эхоплотности - средние (26-28). Явлений возрастной инволюции нет.

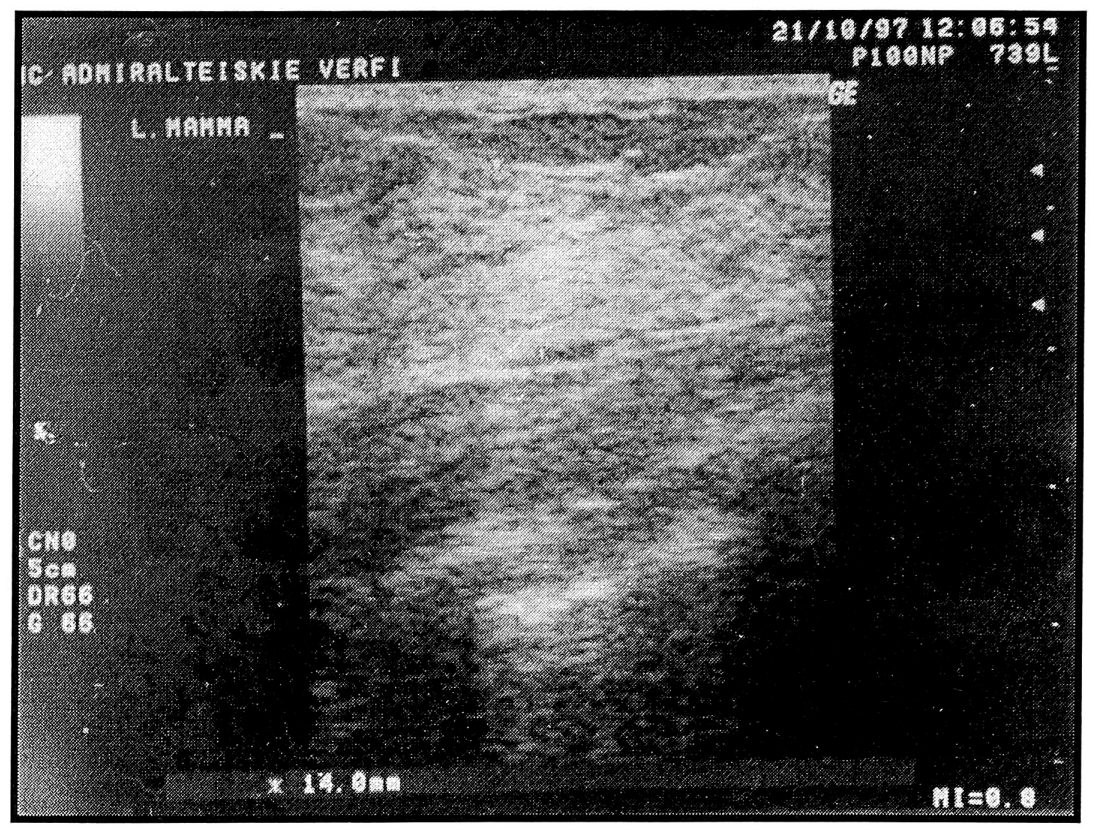

Рис. 4. Эхограмма молочной железы пациентки 45 лет. Предменопаузальный тип строения. Толщина слоя железистой ткани - 10 мм. Показатели эхоплотности - повышенные (35-37). Явления возрастной инволюции - в виде частичной жировой трансформации железистой ткани.

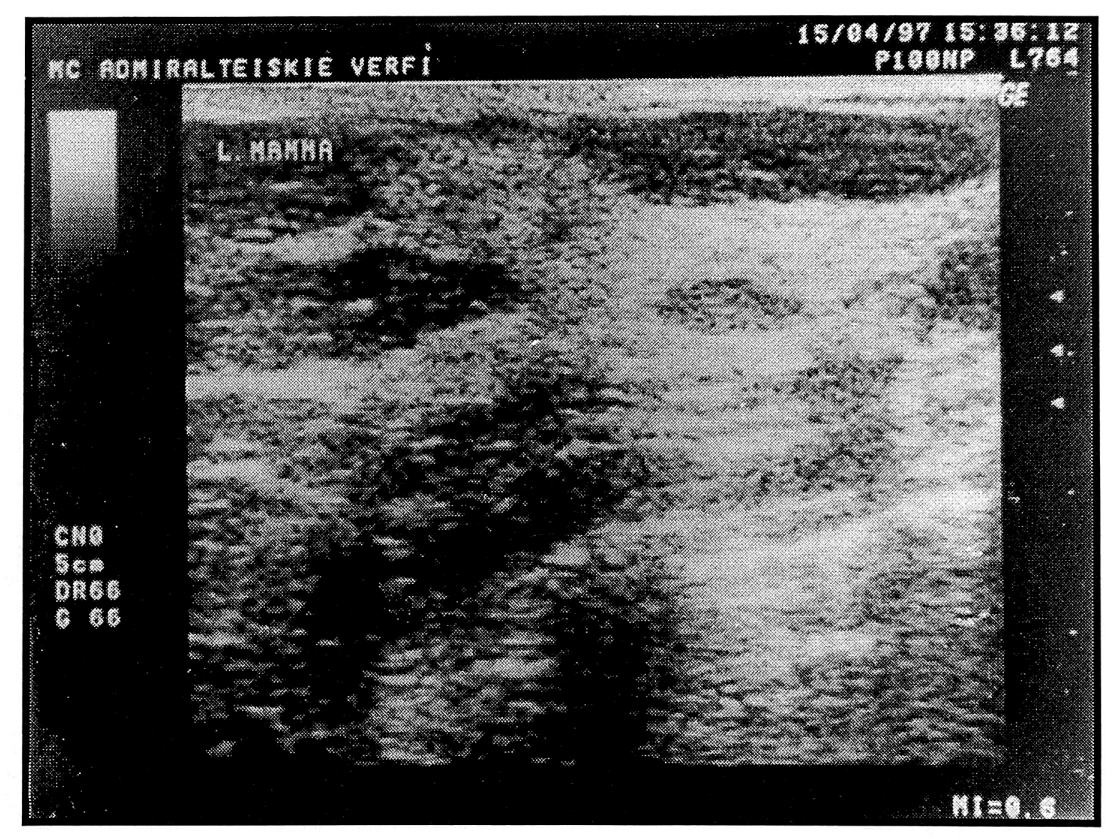


Рис. 5. Эхограмма молочной железы пациентки 63 лет. Постменопаузальный тип строения.

Толщина слоя фиброзной ткани - 6 мм. Показатели эхоплотности - значительно повышенные (41-44). Явления возрастной инволюции - в виде жировой трансформации и фиброзирования тканей молочной железы.

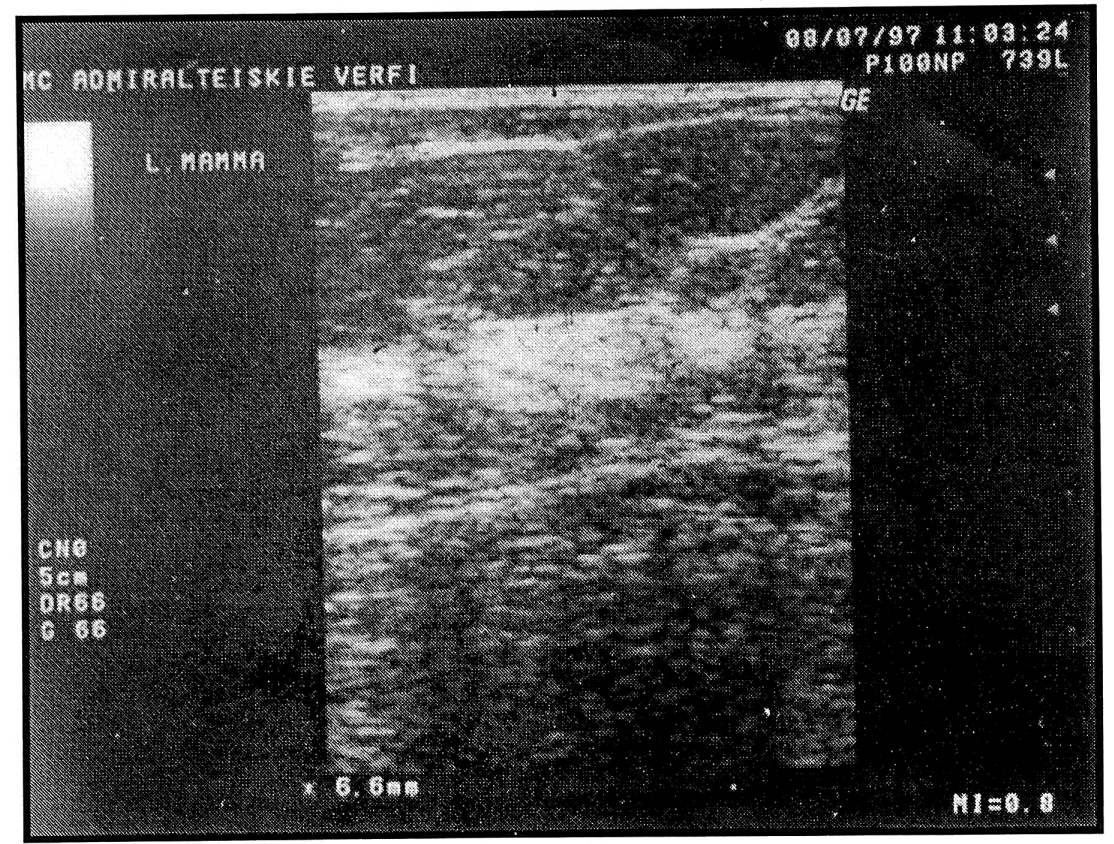

Рис. 6. Эхограмма железистого варианта диффузного фиброаденоматоза у пациентки 30 лет. Утолщение слоя железистой ткани до 19 мм. Показатели эхоплотности - средние (28-30). Отсутствуют явления возрастной инволюции.

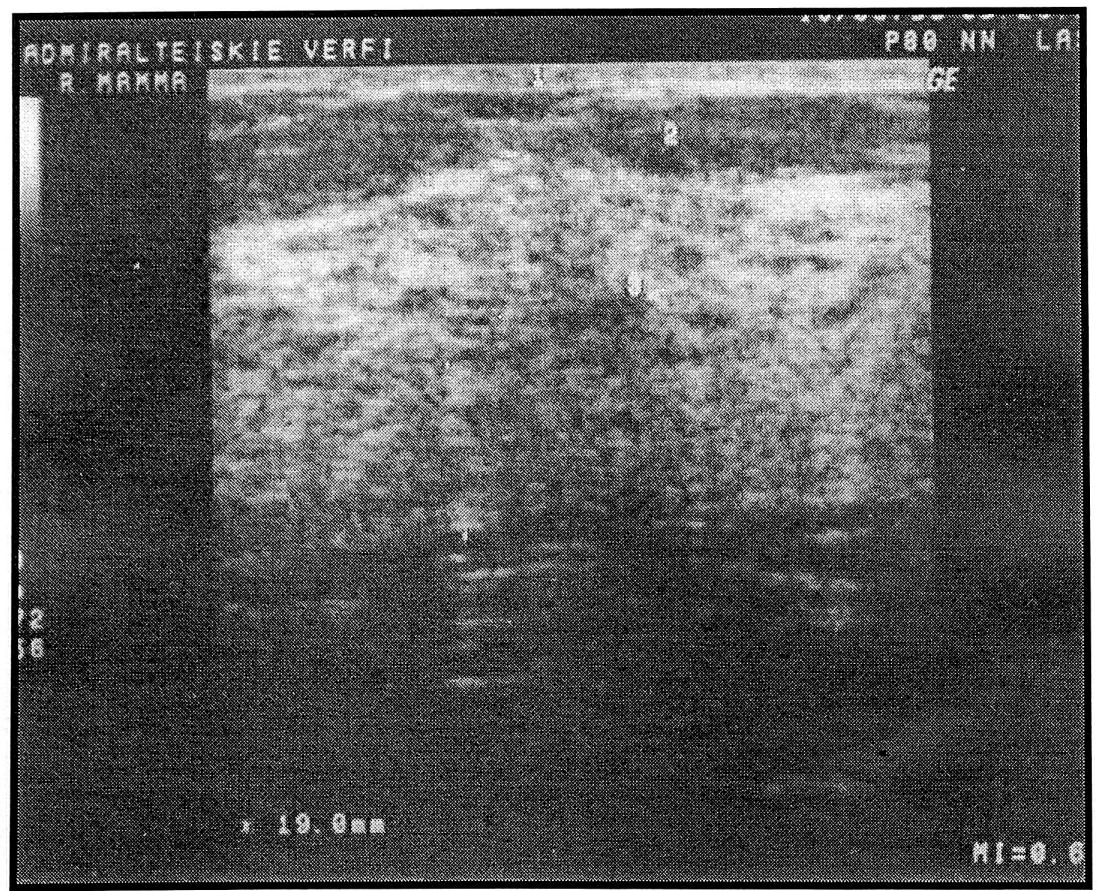

нительнье эхографические симптомь диффузного фиброаденоматоза.

Таким образом, в комплекс әхосимптомов диффузного фиброаденоматоза входят: железистая гиперплазия, фиброзные изменения, наличие кист и дуктэктазия.

Многообразие ультразвуковой картинъ при диффузном фиброаденоматозе обусловлено различньм сочетанием этих симптомов в каждом конкретном случае. По доминированию какого-либо из симптомов мъь въцелили 4 основных эхографических варианта: 1) железистьй; 2) кистозный; 3) фиброзныцй 4) смешанныц.

Каждому эхографическому варианту диффузного фиброаденоматоза соответствует свой симптомокомплекс (табл. 2).

Основным эхографическим симптомом железистого варианта является железистая гиперплазия, которая проявляется утолшением слоя железистой ткани различной степени вьраженности (от 15 до 33 мм ) (рис. 6).

При кистозном варианте доминируюшим эхосимптомом является наличие множественныхкист, в больиинстве случаев выявляемых на фоне фиброзных изменений ткани (повыцение показателей эхоплотности) (рис. 7).

При фиброзном варианте основным эхосимптомом являются фибрознье изменения, проявляюшиеся значительным повышением показателей эхоплотности, которъье не соответствуют возрасту пациенток. В наших исследованиях эти изменения сочетались с утолшением слоя паренхимы молочной железь (рис. 8).

Смешанныцй вариант характеризуется сочетанием всех или больиинства эхосимптомов диффузного фиброаденоматоза (рис. 9).

\begin{tabular}{c} 
Ввьводьи \\
\hline Таким образом, можно утвер- \\
ждать, что эхография имеет ши- \\
рокие возможности в диагности- \\
ке заболеваний молочнъх желез, а
\end{tabular}


Рис. 7. Эхограмма кистозного варианта диффузного ФАМ у пациентки 42 лет. Толщина слоя железистой ткани - 10 мм. Показатели эхоплотности - повышенные (35-37) Мелкие кисты.

Рис. 8. Эхограмма фиброзного варианта диффузного ФАМ у пациентки 34 лет. Утолщение слоя железистой ткани до 16 мм. Показатели эхоплотности - значительно повышенные (41-43).

Рис. 9. Эхограмма смешанного варианта диффузного ФАМ у пациентки 40 лет. Утолщение слоя железистой ткани до 22мм. Киста. Показатели эхоплотности повышенные (35-37) Дуктэктазия. Явлений возрастной инволюции нет.
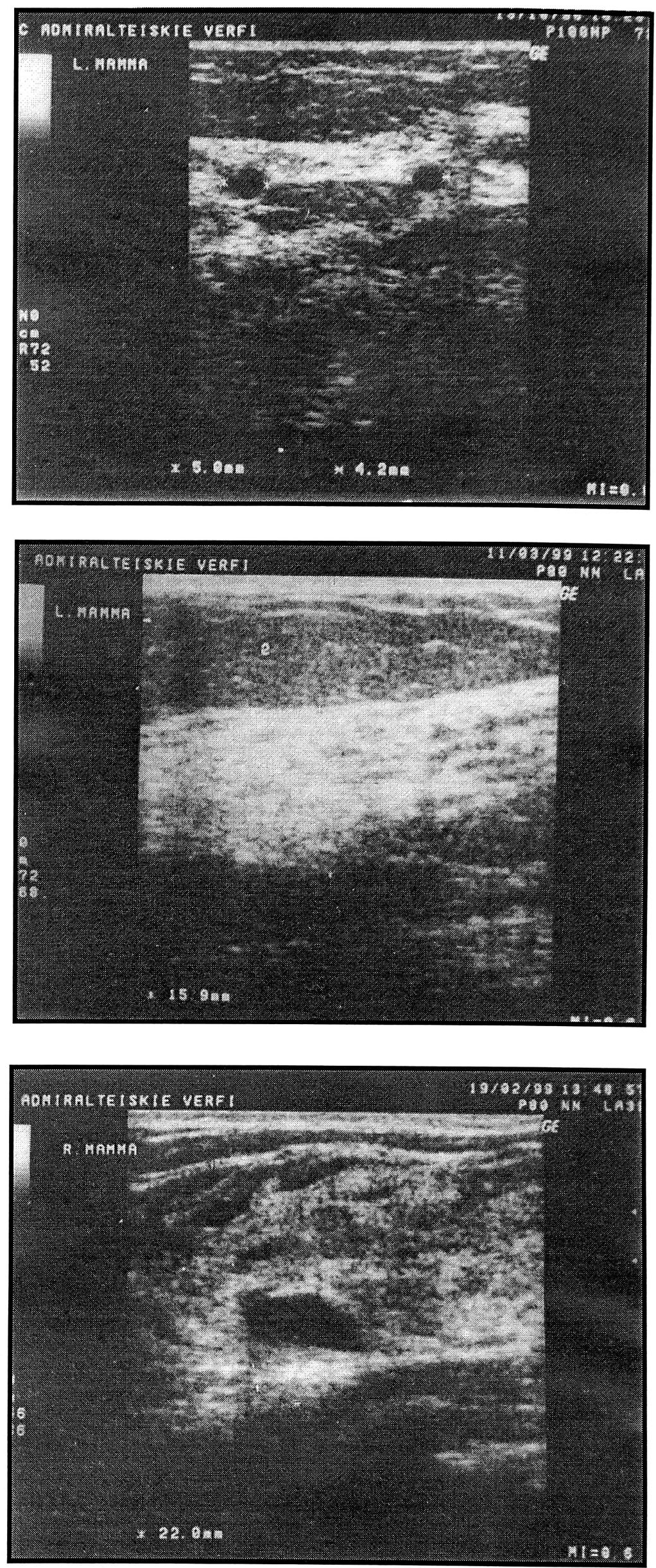
при диффузном фиброаденоматозе является методом выбора.

Применение количественных критериев оценки УЗ-изображения в дополнение к стандартной методике помогает не просто сделать заключение о наличии диффузного фиброаденоматоза, но и четко выделить его эхографический вариант. В процессе динамического наблюдения, опираясь на объективные параметры, возможно вылвлять даже незначительные изменения структуры молочных желез, что отражает эффективность проводимого лечения.

\section{Литература}

1. Митьков В.В., Медведев М.В. Клиническое руководство по ультразвуковой диагностике. - М.: Видар, 1996. - Т.2. - С. 331-367.

2. Шипуло М.Г. Практическое руководство по ультразвуковой диагностике. - М.: Высшая школа, 1995. - C. 174-234.

3. Зайцев А.Н., Веснин А.Г., Семиглазов В.Ф. и др.

Эхографические варианты фиброаденоматоза и диагностика минимальных карцином молочной железы // Вопросы онкологии. 1998. - T. 44. - №2. - С. 198-202.

4. Сидоренко Л.Н. Мастопатия: Психосоматические аспекты. - Л.: Медицина, 1991. - С. 264.

5. Egan R.I. Breast sonography // Breast imaging: diagnosis and morphology of breast diseases. Philadelphia: Saunders, 1988. P.100-125.

6. Leucht W. Teaching Atlas of breast ultrasound. Stuttgart: Thieme Verlag, 1992. 